Article

\title{
Theoretical Investigations of the Interaction of Gaseous Pollutants Molecules with the Polyacrylonitrile Surface
}

\author{
Victor Petrov* and Marta Avilova \\ Southern Federal University, Institute of Nanotechnologies, Electronics and Equipment Engineering, \\ Research and Education and Centre "Microsystem Technics and Multisensor Monitoring Systems", 2, \\ Chekhov St., Taganrog 347922, Russia; m.avir89@yandex.ru \\ * Correspondence: vvp2005@inbox.ru; Tel.: +7-863-437-1624
}

Received: 19 July 2018; Accepted: 11 September 2018; Published: 13 September 2018

\begin{abstract}
This work presents theoretical studies of the interaction of molecules of several gaseous pollutants with polyacrylonitrile (PAN) surface in the presence of a water and/or oxygen molecule. For this purpose, a PAN cluster model has been proposed by the methods of quantum chemical calculations and molecular modeling. The energy-favorable positions, in which the gas molecules are located relative to the surface of the PAN cluster, are determined and the thermodynamic and the following geometric parameters of the systems are calculated: "PAN cluster - oxygen molecule", "PAN cluster - oxygen molecule - gas molecule", "PAN cluster - water molecule - molecule of oxygen", and "PAN cluster - a molecule of water - an oxygen molecule - a gas molecule". It is concluded that PAN in atmospheric air in the presence of oxygen molecules is sensitive to carbon oxide (IV), sulfur (IV) oxide, chlorine, hydrogen sulfide and carbon oxide (II). In an anoxic environment, PAN films will show selective sensitivity to chlorine. The presence of water molecules in the investigated air should not affect the gas sensitivity of PAN films.
\end{abstract}

Keywords: polyacrylonitrile; steric energy; adsorption of gases; molecular modeling; the effect of a molecule of water (oxygen)

\section{Introduction}

It is known that polyacrylonitrile (PAN) under the influence of thermal heating can gradually change its structure [1-4]. PAN films have unique electrical, electrochemical and gas-adsorption properties and are used for various applications in electronic engineering $[5,6]$.

Thin films of PAN that have passed infrared (IR) annealing at temperatures of $300-600{ }^{\circ} \mathrm{C}$ have semiconductor and gas sensitive properties already at room temperature [5,7-13]. Such materials can be used in energy-efficient gas sensors to monitor air quality [10,11]. The mechanism of interaction of molecules of simple gases with the surface of PAN was investigated using quantum chemical calculations. For this purpose, the authors of references [14,15] calculated the structure of a single-atomic PAN layer using a semiempirical quantum chemical calculation scheme MNDO (Modified Neglect of Diatomic Overlap). The PAN cluster consisted of five carbon rings in length and four in width. However, in one of the long rows, instead of five there were six rings. The mechanisms of adsorption of fluorine, oxygen and hydrogen molecules to the surface of the PAN cluster were investigated. The authors noted that on the surface of a single-layer cluster of PAN, molecules of gases are adsorbed by the mechanism of chemical adsorption. Here, a cluster was also modeled, consisting of two identical layers of PAN, which were located one above the other. It was shown that a physical adsorption of simple gas molecules can occur on a two-layer PAN cluster [16]. 
Adsorption of the triatomic nitrogen oxide molecule $\left(\mathrm{NO}_{2}\right)$ was considered in reference [7]. A single-layer PAN cluster consisting of seven rings, one of which is located at the center, with the other six around it, was obtained by quantum chemical calculations. During the adsorption of the $\mathrm{NO}_{2}$ molecule, a surface adsorption complex was formed with the arrangement of the nitrogen dioxide molecule at a minimum distance of $2.37 \AA$ from the nearest hydrogen atom of the PAN cluster. However, the coordination of the nitrogen atom of the molecule occurred over the center of one of the rings. Judging from the calculated distances between the gas molecule and the cluster, physical adsorption took place.

The mechanism of adsorption of a triatomic carbon monoxide (IV) molecule on the surface of a two-layer cluster of PAN was considered in reference [17]. Quantum-chemical calculations have shown that for a $\mathrm{CO}_{2}$ molecule only physical adsorption at a distance of $2.5 \AA$ from the center of the ring of the PAN cluster is possible.

The results of references [7,17] were confirmed in reference [18], in which it was shown that both molecules $\left(\mathrm{CO}_{2}\right.$ and $\left.\mathrm{NO}_{2}\right)$ are actually adsorbed by the mechanism of physical adsorption. The calculated length $\left(l_{\min }\right)$ of the bond formed was somewhat larger-3.7 and $4 \AA$ for $\mathrm{CO}_{2}$ and $\mathrm{NO}_{2}$, respectively. In both cases, the molecules of gases were adsorbed to the center of the ring. However, in reference [18] another two-layer cluster of PAN was simulated, consisting of two linear pentamers of PAN arranged one above the other [18]. A simpler form of the cluster made it possible to perform quantum-chemical calculations for a larger number of gas molecules. Adsorption of other molecules of pollutant gases (nitric oxide (IV), methane, ammonia, sulfur oxide (II), hydrogen sulfide, ozone, carbon oxide (II), chlorine) on the PAN surface was investigated. For all gas molecules, with the exception of the ammonia molecule, their location above the cluster surface at a distance of 3.4 to $4 \AA$ was energetically advantageous. The binding energy $\Delta \mathrm{E}$ for most gas molecules was not higher than $13 \mathrm{~kJ} / \mathrm{mol}$, which indicated physical adsorption due to van der Waals forces. The adsorption of the ammonia molecule proved to be energetically unfavorable. The steric energy of the PAN cluster (EPAN, which was equal to $2795.7 \mathrm{~kJ} / \mathrm{mol}$ ) and the "PAN - gas molecule cluster" (EPN+gas) system were calculated. It was concluded that PAN films are selectively sensitive to chlorine, since only the "PAN cluster - chlorine molecule" system had a steric energy of $\mathrm{E}_{\mathrm{PAN}+\mathrm{Cl}_{2}}$ equal to $2477.1 \mathrm{~kJ} / \mathrm{mol}$, that is, less than EPAN.

At the same time, under real conditions, molecules of water and oxygen are always present on the surface of gas sensitive materials, which affects the mechanism of interaction of gas molecules with the surface of gas-sensitive materials [19]. In reference [20], the influence of the water molecule on the interaction of PANs with the molecules of these gases was estimated by analogous methods. It was shown that the water molecule is more advantageous at a distance of $2.7 \AA$ from the center of the PAN cluster. However, the steric energy of the "PAN cluster - water molecule" system $\left(E_{P A N+H_{2} O}\right)$ was significantly higher than the $\mathrm{E}_{\mathrm{PAN}}$, and was $6123.39 \mathrm{~kJ} / \mathrm{mol}$. In the interaction of a PAN cluster with molecules of pollutant gases in the presence of a water molecule, the steric energy of the "PAN cluster - water molecule - gas molecule" $\left(\mathrm{E}_{\mathrm{PAN}+\mathrm{H}_{2} \mathrm{O}+\text { gas }}\right)$ system was estimated. The authors of reference [20] concluded that, in the presence of water molecules, PAN films can have a selective gas sensitivity to carbon oxide (II) molecules, since only when interacting with the CO molecule the steric energy

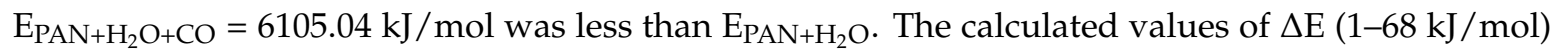
and $l_{\min }(>3.2 \AA)$ also indicated van der Waals interactions between the gas molecule and the PAN surface. High values of $\Delta \mathrm{E}$ were characteristic of polar molecules, for which electrostatic forces are also possible [21].

However, in references $[18,20]$ the effect of oxygen molecules on the processes of adsorption of gas-pollutant molecules on the PAN surface was not investigated. Oxygen, as is known, is constantly present in the environment. In addition, the simultaneous influence of oxygen and water molecules on adsorption of molecules of pollutant gases was not studied.

In connection with this, the aim of this paper is a theoretical study of the mechanisms of interaction of the PAN cluster with the molecules of the main pollutant gases (nitric oxide (IV), methane, ammonia, 
sulfur oxide (II), hydrogen sulfide, ozone, carbon monoxide (IV), carbon monoxide (II), chlorine) in the presence of an oxygen molecule or with the simultaneous presence of an oxygen molecule and a water molecule.

\section{Materials and Methods}

The studies were carried out according to the method proposed in references $[18,20,22]$. The PAN cluster consisting of two macromolecules, PAN pentamers, arranged one above the other was obtained by the method of quantum chemical calculations in the HyperChem program using the semiempirical quantum chemical calculation scheme MNDO [23,24]. Spatial configurations of PAN macromolecules were obtained [22]. Further, in the GAUSSIAN09 software package, using the $6-31 \mathrm{G} *$ basic set within the density functional theory (DFT), which allows the most accurate calculation of the energy of the correlated electron motion thermodynamic parameters of these macromolecules were calculated [22]. Then, by the molecular modeling method (the method of minimizing the potential energy of the system in the modified version of the force field (MM2) developed by Allinger, a model of the cluster of PAN was obtained in subroutine Chem3D of program Chemoffice. Using it, the possibility of interaction of PAN with molecules of gases-pollutants [18] and interaction of PAN with gas molecules-pollutants in the presence of water molecules was estimated [20]. Semiempirical calculations of the spatial configurations of macromolecules were carried out using the exchange correlation functional B3LYP (the correlation functionals LYP and VWN and the exchange functionals Becke + Slater $+\mathrm{HF}$ ) include the dependence of the correlation energy of the electron density derivative and the exchange energy $[18,20,22,25-28]$.

At the first stage, the interaction of the PAN cluster was modeled with the oxygen molecule, then with simultaneous presence of oxygen and water molecules. Figure 1 shows the positions that were set for the oxygen and/or water molecule or for the gas molecules. Position (1) - the gas molecule is located inside the cluster. The positions (2)-(12) of the molecule were above the surface of the middle of the cluster with distances from $2 \AA$ to $10 \AA$.

(12) $l=10 \AA$

(2) $l=2 \AA$

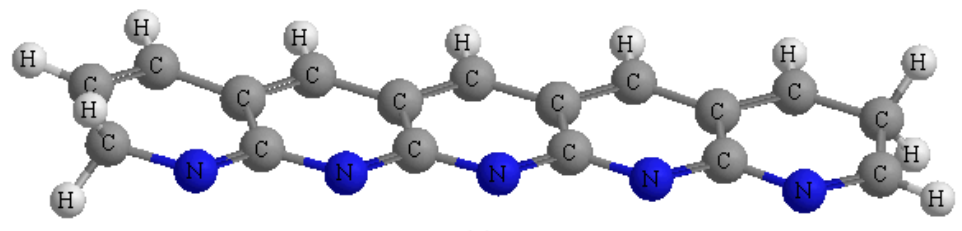

(1)

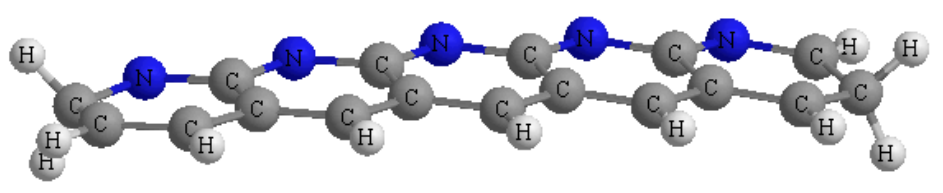

Figure 1. Arrangement of gas molecules in interaction with the surface of a polyacrylonitrile (PAN) cluster.

Further, thermodynamic and geometric indicators of the systems include "cluster PAN - oxygen molecule" and "PAN cluster - water molecule - oxygen molecule", namely, the steric energy of this system $\left(\mathrm{E}_{\mathrm{PAN}+\mathrm{O}_{2}}\right.$ and $\left.\mathrm{E}_{\mathrm{PAN}+\mathrm{O}_{2}+\mathrm{H}_{2} \mathrm{O}}\right)$, the binding energy between the water molecule and the surface of the PAN cluster $(\Delta \mathrm{E})$, and the distance $\left(\mathrm{l}_{\mathrm{min}}\right)$. Figure 2 shows the model of the "PAN cluster - water molecule - oxygen molecule" system. 


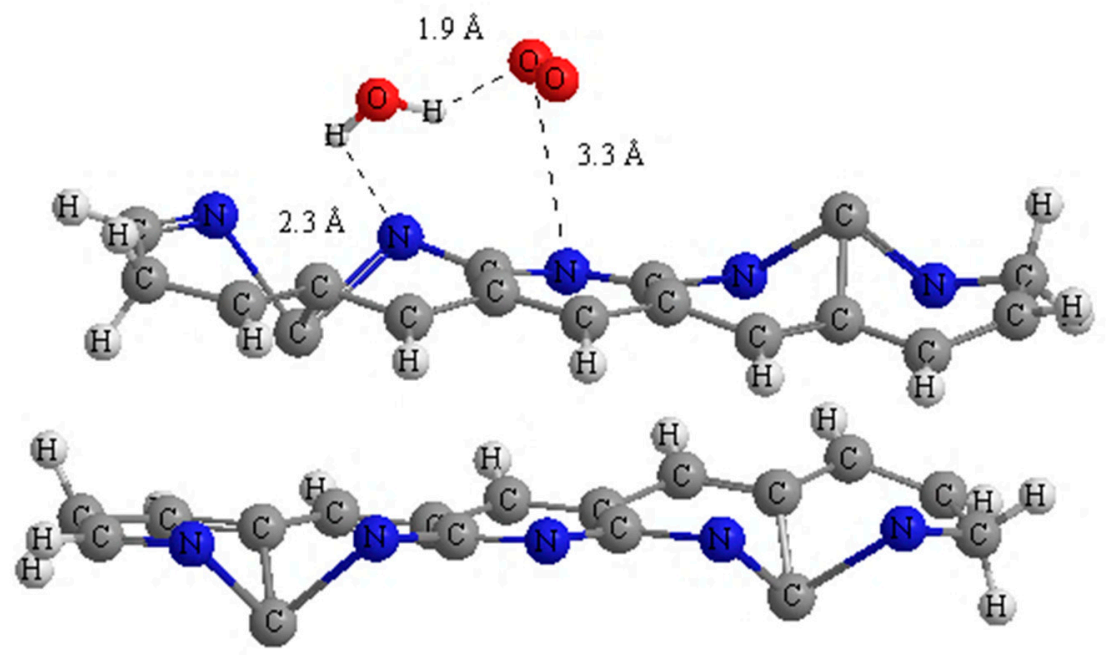

Figure 2. The location of oxygen and water molecules in the "PAN cluster - water molecule - oxygen molecule" system.

At the last stage, molecular systems were used to study these systems: "PAN cluster - oxygen molecule - gas molecule" and "PAN cluster - water molecule - oxygen molecule - gas molecule". Based on the results of comparison of thermodynamic parameters of the investigated systems, first of all their steric energies, the possibility of interaction of gas molecules-pollutants with PAN was estimated.

\section{Results and Discussion}

As a result of molecular modeling of the "PAN cluster - oxygen molecule - gas molecule" system, it was established that the location of the oxygen molecule at a distance of $3.4 \AA$ above the surface in the middle of the PAN cluster is energetically favorable. This indicates a physical adsorption of the oxygen molecule and does not contradict the results of reference [16], which shows that the adsorption of an oxygen molecule on a two-layer PAN cluster, but of a larger size, occurs at a distance of $3 \AA$.

The results of calculations of the thermodynamic and geometric parameters of the "PAN cluster - oxygen molecule - gas molecule" system are presented in Table 1 and Figure 3. The steric energy of the system "PAN cluster - oxygen molecule" $\left(\mathrm{E}_{\mathrm{PAN}+\mathrm{O}_{2}}\right)$ is $2387.71 \mathrm{~kJ} / \mathrm{mol}$, which is less than $\mathrm{E}_{\mathrm{PAN}}$. This suggests that the effect of oxygen molecules on the interaction of gas molecules with the PAN surface can be significant.

Table 1. Parameters of the "PAN cluster - molecule of oxygen - molecule of gas" system.

\begin{tabular}{ccccc}
\hline No & Gas Molecule & $\left.\mathbf{E}_{\text {min }}, \mathbf{( k J} / \mathbf{m o l}\right)$ & $\Delta \mathrm{E}, \mathbf{( k J} / \mathbf{m o l})$ & $\mathbf{1}_{\text {min }}, \mathbf{\AA}$ \\
\hline 1 & $\mathrm{NO}_{2}$ & 8440.25 & 5.15 & 6 \\
2 & $\mathrm{Cl}_{2}$ & $\mathbf{2 3 7 3 . 4 3}$ & 0.79 & 6 \\
3 & $\mathrm{NH}_{3}$ & 4729.17 & 15.04 & 3.2 \\
4 & $\mathrm{CH}_{4}$ & 3938.77 & 5.03 & 3 \\
5 & $\mathrm{SO}_{2}$ & $\mathbf{2 3 7 1 . 9 6}$ & $\mathbf{5 6 . 6 9}$ & 3 \\
6 & $\mathrm{H}_{2} \mathrm{~S}$ & $\mathbf{2 3 7 3 . 7 2}$ & 4.52 & $\mathbf{2 . 5}$ \\
7 & $\mathrm{CO}$ & $\mathbf{2 3 7 6 . 6 9}$ & 2.30 & 3.2 \\
8 & $\mathrm{O}_{3}$ & 3235.73 & 5.03 & 3.2 \\
9 & $\mathrm{CO}_{2}$ & $\mathbf{2 3 6 9 . 7 8}$ & 2.80 & 3.2 \\
\hline
\end{tabular}




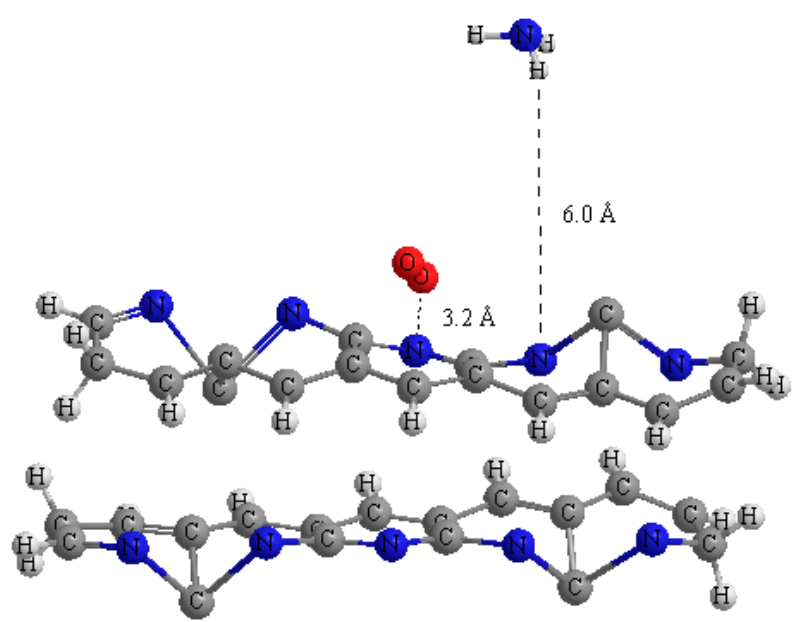

Figure 3. The location of the ammonia molecule in the "PAN cluster - oxygen molecule - gas molecule" system.

Comparing the values of the steric energies of the system $\mathrm{E}_{\mathrm{PAN}+\mathrm{O}_{2}}+$ gas and $\mathrm{E}_{\mathrm{PAN}+\mathrm{O}_{2}}$, it can be concluded that, in the presence of oxygen molecules, PAN films will exhibit a gas sensitivity to carbon monoxide (IV), sulfur (IV) oxide, chlorine, hydrogen sulfide and carbon monoxide (II). At the same time, in the "PAN cluster - oxygen molecule - $\mathrm{SO}_{2}$ molecule" system, a high binding energy $\left(56.69 \mathrm{~kJ} / \mathrm{mol}\right.$ ) between the $\mathrm{SO}_{2}$ molecule and the PAN surface is observed. This can be explained by the manifestation of electrostatic forces due to the high dipole moment of the $\mathrm{SO}_{2}$ molecule of $1.61 \mathrm{D}$ [28]. It is known that polar molecules of gases can interact with the surface of gas-sensitive materials with an interaction energy reaching $200 \mathrm{~kJ} / \mathrm{mol}$ [29].

The calculated distances between the gas molecule and the oxygen molecule exceed $2.9 \AA$. This shows that the oxygen molecule does not affect the molecules of gases. The values of $1_{\text {min }}$ $(>2.5 \AA)$ and $\Delta \mathrm{E}(0.79-56.69 \mathrm{~kJ} / \mathrm{mol})$ also indicate van der Waals interactions between the gas molecule and the PAN surface.

Further, by the method of molecular modeling, the "PAN cluster - water molecule - molecule of oxygen - gas molecule" system was investigated. Here, the minimum distances between the gas molecule and the water molecule $\left(\mathrm{L}_{1}\right)$, and between the gas molecule and the oxygen molecule $\left(\mathrm{L}_{2}\right)$ were estimated. The results of the simulation are presented in Table 2 and in Figure 4. According to the results obtained, it is established that the steric energy of the "PAN - oxygen molecule - water molecule" system is $\mathrm{E}_{\mathrm{PAN}+\mathrm{O}_{2}+\mathrm{H}_{2} \mathrm{O}}=5092.65 \mathrm{~kJ} / \mathrm{mol}$, which is higher than $\mathrm{E}_{\mathrm{PAN}}$ and $\mathrm{E}_{\mathrm{PAN}+\mathrm{O}_{2}}$, but less than $\mathrm{E}_{\mathrm{PAN}+\mathrm{H}_{2} \mathrm{O}}$.

Table 2. Thermodynamic parameters of the "PAN cluster - oxygen molecule - water molecule - gas molecule" system.

\begin{tabular}{|c|c|c|c|c|c|c|}
\hline No & Gas Molecule & $\mathrm{E}_{\min },(\mathrm{kJ} / \mathrm{mol})$ & $\Delta \mathrm{E},(\mathrm{kJ} / \mathrm{mol})$ & $1_{\min }, \AA$ & $\mathrm{L}_{1}, \AA\left(\mathrm{H}_{2} \mathrm{O}\right)$ & $\mathrm{L}_{2}, \AA\left(\mathrm{O}_{2}\right)$ \\
\hline 1 & $\mathrm{NO}_{2}$ & 8874.96 & 208.75 & 2.5 & 3.6 & 5.2 \\
\hline 2 & $\mathrm{Cl}_{2}$ & 5131.37 & 3.60 & 6 & 2.6 & 3.9 \\
\hline 3 & $\mathrm{NH}_{3}$ & 8621.55 & 9.13 & 4 & 2.5 & 4.5 \\
\hline 4 & $\mathrm{CH}_{4}$ & 7358.27 & 3.69 & 6 & 2.2 & 4.5 \\
\hline 5 & $\mathrm{SO}_{2}$ & 4994.14 & 12.82 & 3 & 3.2 & 4.3 \\
\hline 6 & $\mathrm{H}_{2} \mathrm{~S}$ & 4434.61 & 9.18 & 3.7 & 2.4 & 5.5 \\
\hline 7 & $\mathrm{CO}$ & 5093.91 & 0.84 & 4 & 3 & 5.3 \\
\hline 8 & $\mathrm{O}_{3}$ & $15,118.32$ & 0.00 & 10 & 3.9 & 5.3 \\
\hline 9 & $\mathrm{CO}_{2}$ & 4820.93 & 30.21 & 3.2 & 2.2 & 5.3 \\
\hline
\end{tabular}




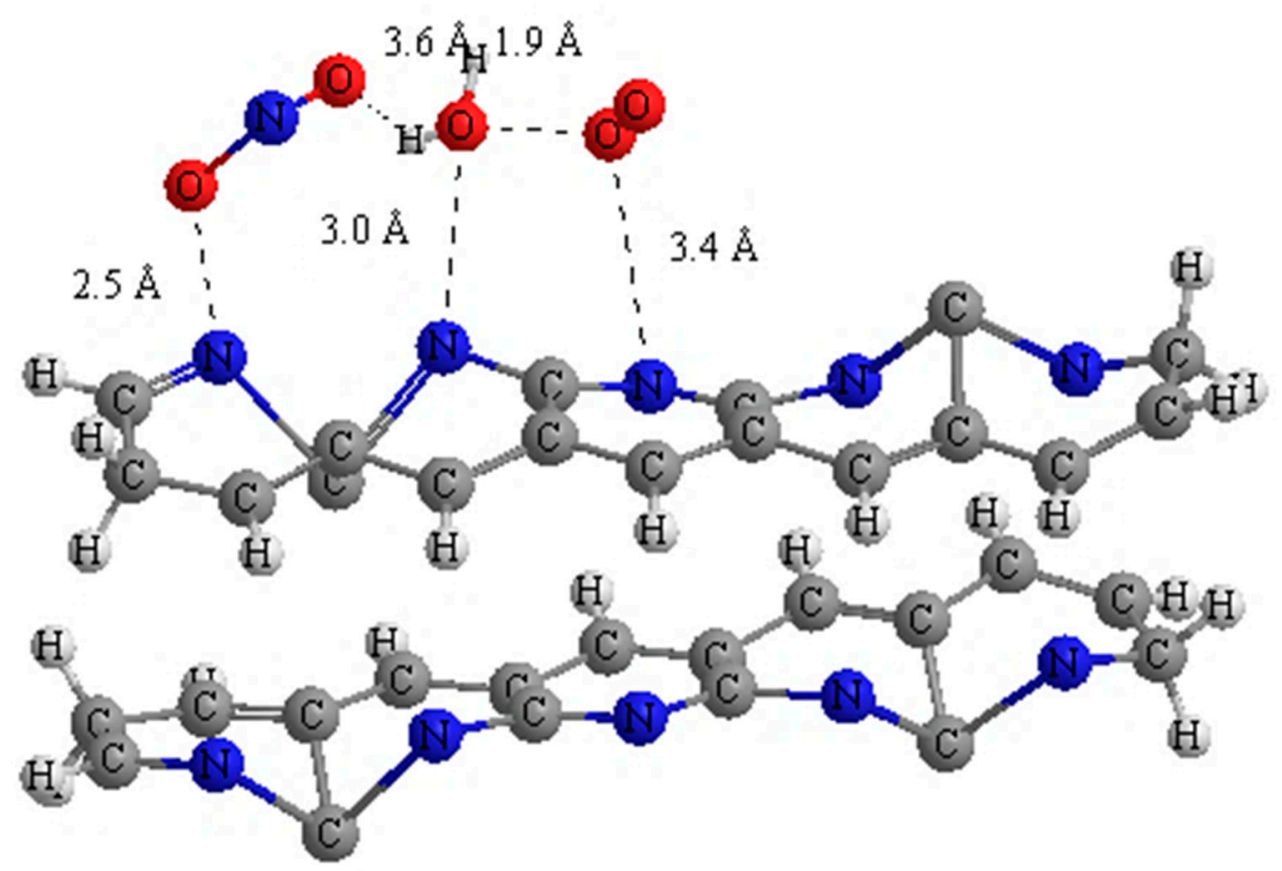

Figure 4. The location of the nitrogen dioxide molecule in the "PAN cluster - water molecule oxygen molecule - gas molecule" system.

The calculated distances between the gas molecule and the water molecule $\left(\mathrm{L}_{1}\right)$ show the influence of the water molecule, which attracts molecules of gases such as $\mathrm{CO}_{2}, \mathrm{H}_{2} \mathrm{~S}, \mathrm{NH}_{3}$, and $\mathrm{Cl}_{2}$ due to its high dipole moment of $1.49 \mathrm{D}$ [28]. $\mathrm{L}_{1}$ in this case is in the range of 2.2-2.6 $\AA$. At the same time, the distance between the molecules of these gases and the PAN surface $\left(l_{\min }\right)$ is more than $3.2 \AA$.

The effect of the oxygen molecule in this system is low, since the distance between the gas molecule and the oxygen molecule $\left(\mathrm{L}_{2}\right)$ is above $3.9 \AA$. The calculated values of $\Delta \mathrm{E}$ also indicate the action of van der Waals forces. Furthermore, simultaneous influence of water and oxygen molecules leads to the fact that the binding energy $\triangle \mathrm{E}$ in the "PAN cluster - oxygen molecule - water molecule - nitrogen dioxide molecule" system is the highest $(\Delta \mathrm{E}=208.75 \mathrm{~kJ} / \mathrm{mol})$, and $l_{\min }$ is the lowest $\left(l_{\min }=2.5 \AA\right)$. This behavior may be due to the fact that the $\mathrm{NO}_{2}$ molecule is polar with a dipole moment of $0.33 \mathrm{D}$ [28], and a high value of $\Delta \mathrm{E}$ is a consequence of the manifestation of electrostatic interaction forces.

A joint analysis of the results is presented in references [18,20], and the results of this paper showed that near the PAN surface, oxygen molecules are more likely to be located, since the steric energy of the "PAN - oxygen molecule" $\left(\mathrm{E}_{\mathrm{PAN}+\mathrm{O}_{2}}\right)$ system is the smallest of all the systems examined. The presence of water molecules in the investigated air should not affect the gas sensitivity of PAN films, since the steric energy of the "PAN cluster - water molecule - gas molecule" system is much higher. In this regard, the highest sensitivity in PAN in atmospheric air will be to carbon monoxide (IV), sulfur (IV) oxide, chlorine, hydrogen sulfide and carbon monoxide (II).

The theoretical results on the interaction of gas-pollutant molecules with PAN films that have passed IR annealing obtained in this paper were experimentally confirmed earlier in references $[5,7,10,11,30]$. It was shown in references $[7,10,30]$ that the minimum measured concentration of chlorine was $0.14 \mathrm{ppm}$, and under the action of nitrogen dioxide it was $14 \mathrm{ppm}$. This means that the selective sensitivity of PAN films to chlorine is two orders of magnitude higher than that of nitrogen dioxide. In reference [10], the authors also noted the reaction of gas sensors based on PAN films to sulfurous gas at a concentration above $50 \mathrm{ppm}$. At the same time, the response of the sensors to the action of ammonia, carbon monoxide (II), and ozone was absent. In reference [5], a significant effect of carbon oxide (II) on the resistance of pyrolyzed PAN is shown. It was established in references [7,11] that, for gas sensors based on PAN films subjected to IR annealing, the effect of humidity in the range from 43 to $85 \%$ does not affect the gas sensitivity of the sensor. 
As a result of quantum chemical calculations and molecular modeling, it has also been established that the introduction of molecules of gas-pollutants, water or oxygen molecules into the PAN structure is unlikely because of the relatively high steric energy of the system (2-3 times higher

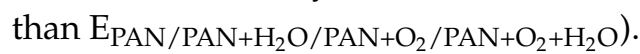

\section{Conclusions}

In this work, a theoretical study of the mechanisms of interaction of the PAN cluster with the molecules of the main pollutant gases (nitric oxide (IV), methane, ammonia, sulfur (II) oxide, hydrogen sulfide, ozone, carbon monoxide (IV), carbon monoxide (II), chlorine) in the presence of an oxygen molecule or with the simultaneous presence of an oxygen molecule and a water molecule was carried out.

As a result of quantum chemical calculations and molecular modeling, it was established that PAN in the presence of oxygen molecules has a sensitivity to carbon oxide (IV), sulfur (IV) oxide, chlorine, hydrogen sulfide and carbon oxide (II). The mechanism of interactions between gas molecules and the PAN surface is van der Waals interaction, since the binding energies of $\Delta \mathrm{E}$ do not generally exceed $20-40 \mathrm{~kJ} / \mathrm{mol}$. In the case of polar molecules, the manifestation of electrostatic interaction forces is possible, then the binding energy can reach $200 \mathrm{~kJ} / \mathrm{mol}$. The presence of water molecules in the investigated air does not affect the gas sensitivity of PAN films.

Author Contributions: V.P. defined the tasks of the experiment, analyzed the results and compiled research findings; M.A. made quantum-chemical calculations and carried out molecular modeling of the systems under study.

Funding: This work was supported by a grant from the South Federal University No VnGr-07/2017-21.

Conflicts of Interest: The authors declare no conflict of interest. The funders had no role in the design of the study; in the collection, analyses, or interpretation of data; in the writing of the manuscript, and in the decision to publish the results.

\section{References}

1. Zemtsov, L.M.; Karpacheva, G.P. Chemical transformations of polyacrylonitrile under the action of incoherent infrared radiation. Polym. Sci. Ser. A 1994, 36, 919-924.

2. Kozlov, V.V.; Karpacheva, G.P.; Petrov, V.S.; Lazovskaya, E.V. Formation of polyconjugated bonds in polyacrylonitrile by thermal treatment in vacuum. Polym. Sci. Ser. A 2001, 43, 20-26.

3. Laffont, L.; Monthioux, M.; Serin, V.; Mathur, R.B.; Guimon, C.; Guimon, M.F. An EELS study of the structural and chemical transformation of PAN polymer to solid carbon. Carbon 2004, 42, 2485-2494. [CrossRef]

4. Yoshida, H.; Sato, N. Deposition of Acrylonitrile Cluster Ions on Solid Substrates: Thin Film Formation by Intracluster Polymerization Products. J. Phys. Chem. B 2006, 110, 4232-4239. [CrossRef] [PubMed]

5. Kozhitov, L.V.; Krapukhin, V.V.; Karpacheva, G.P.; Pavlov, S.A.; Kozlov, V.V. Nanotechnology based on metal-carbon nanocomposites and carbon nanocrystalline materials is a step into the future of electronics. Mater. Electron. Eng. 2005, 3, 64-67.

6. Muratov, D.G.; Kozlov, V.V.; Krapukhin, V.V.; Kozhitov, L.V.; Karpacheva, G.P.; Zemtsov, L.M. Investigation of electrical conductivity and semiconductor properties of a new carbon material based on IR-pyrolyzed polyacrylonitrile $\left(\left(\mathrm{C}_{3} \mathrm{H}_{3} \mathrm{~N}\right)_{n}\right)$. Mater. Electron. Eng. 2007, 3, 26-31.

7. Lu, P.; Yu, G.A.; Semenistaya, T.V.; Vorobyov, E.V.; Korolev, A.N. Obtaining sensitive elements of gas sensors based on polyacrylonitrile and silver-containing polyacrylonitrile films and determining their characteristics. Nano Microsyst. Technol. 2011, 9, 5-12.

8. Konovalenko, S.P.; Bednaya, T.A.; Semenistaya, T.V.; Petrov, V.V.; Maraeva, E.V. Development of the technology for obtaining non-heated gas sensors based on polyacrylonitrile for hybrid sensor systems. Eng. Bull. Don 2012, 23, 13.

9. Semenistaya, T.V. Polyacrylonitrile-based materials: Properties, Methods and Applications. Adv. Mater. 2016, 175, 61-77.

10. Petrov, V.V.; Semenistaya, T.V. Metal-Containing Polyacrylonitrile: Composition, Structure, Properties; Publishing House SFedU: Taganrog, Russia, 2015; p. 169. 
11. Semenistaya, T.V.; Petrov, V.V.; Bednaya, T.A. Energy-Efficient Gas Sensors Based on Nanocomposite Organic Semiconductors; Publishing House SFedU: Taganrog, Russia, 2013; p. 120.

12. Luoh, H.; Hahn, T. Electrospun nanocomposite fiber mats as gas sensors. Compos. Sci. Technol. 2006, 66, 2436-2441. [CrossRef]

13. Falchary, M.M.; Plugotarenko, N.K.; Petrov, V.V. Simulation of the formation process of conductive organic polymeric materials for gas sensor systems. Adv. Mater. Res. 2013, 838-841, 3273-3276. [CrossRef]

14. Kozlov, V.V.; Kozhitov, L.V.; Krapuhin, D.G.; Zaporotskova, I.V.; Davletova, O.A.; Muratov, D.G. Proton conductivity of carbon nanostructures based on pyrolyzed polyacrylonitrile and its practical application. Mater. Electron. Eng. 2008, 1, 59-65.

15. Kozhitov, L.V.; Viet, N.H.; Kozlov, V.V.; Emelyanov, S.G. The Structure and Content Peculiarities of Carbon Material Obtained under the Polyacrylonitrile Infra-red Heating. J. Nano Electron. Phys. 2013, 5, 04020.

16. Anikeev, N.A.; Zaporotskova, I.V. Quantum-chemical calculations of processes of adsorption of simple gas phase molecules on the surface of pyrolysated polyacrylonitrile. Sci. J. Volgogr. State Univ. Technol. Innov. 2013, 1, 22-27.

17. Zaporotskova, I.V.; Anikeev, N.A.; Boroznina, N.P. Sensory device based on pyrolyzed polyacrylonitrile for carbon dioxide test. Sci. J. Volgogr. State Univ. Technol. Innov. 2016, 4, 30-39.

18. Avilova, M.M.; Petrov, V.V. Molecular modeling and quantum chemical calculations of interaction of gas pollutants with polyacrylonitrile. Russ. J. Phys. Chem. B 2018, 12, 281-284. [CrossRef]

19. Barsan, N.; Weimar, U. Understanding the fundamental principles of metal oxide based gas sensors; the example of $\mathrm{CO}$ sensing with $\mathrm{SnO}_{2}$ sensors in the presence of humidity. J. Phys. Condens. Matter 2003, 15, 813-839. [CrossRef]

20. Avilova, M.M.; Petrov, V.V. Investigation of the interaction of gas molecules with the surface of polyacrylonitrile in the presence of water molecules. Izvestiya SFedU. Eng. Sci. 2018, 2, 47-54. [CrossRef]

21. Gerasimov, Y.I.; Dreving, V.P.; Eremin, E.N.; Kisilev, A.V.; Lebedev, V.P.; Panchenkov, G.M.; Shlygin, A.I. Course of Physical Chemistry. Chemistry 1964, 1, 624.

22. Avilova, M.M.; Petrov, V.V. A Study of Gas-Sensitive Properties of Cobalt-Modified Polyacrylonitrile Films by the Methods of Molecular Modeling and Quantum Chemistry. Russ. J. Phys. Chem. B 2017, 11, 618-623. [CrossRef]

23. Dewar, M.J.S.; Thiel, W. Ground states of molecules. 38. The MNDO method. Approximations and parameters. J. Am. Chem. Soc. 1977, 99, 4899-4907. [CrossRef]

24. Dewar, M.J.S.; Thiel, W. A semiempirical model for the two-center repulsion integrals in the NDDO approximation. Theor. Chem. Acta 1977, 46, 89-104. [CrossRef]

25. Parr, R.G.; Yang, W. Density Functional Theory of Atoms and Molecules; Oxford University Press: Oxford, UK, 1989; p. 333.

26. Kittel, C. Quantum Theory of Solids; Nauka: Moscow, Russia, 1967; p. 493.

27. Zaporotskova, I.V.; Kojitov, L.V.; Anikeev, N.A.; Kojitov, L.V.; Davletova, O.A.; Popkova, A.V. Theoretical studies of the structure of the metal-Carbon composites on the base of acryle-Nitrile nanopolimer. J. Nano Electron. Phys. 2014, 6, 03035-03036.

28. Nikolsky, B.P. Handbook of the chemist. Chemistry 1976, 1, 1071.

29. Petrov, V.V. Investigation of the features of the interaction of gas molecules with the surface of oxide gas sensitive materials. Nano Microsyst. Technol. 2007, 1, 24-27.

30. Bednaya, T.A.; Konovalenko, S.P.; Semenistaya, T.V.; Petrov, V.V.; Korolev, A.N. Gas-sensitive elements of a nitrogen dioxide and chlorine sensor based on cobalt-containing polyacrylonitrile. Proc. Univ. Electron. 2012, 4, 66-71.

(C) 2018 by the authors. Licensee MDPI, Basel, Switzerland. This article is an open access article distributed under the terms and conditions of the Creative Commons Attribution (CC BY) license (http:/ / creativecommons.org/licenses/by/4.0/). 